\title{
Karyotype analysis and optimization of mitotic index in Picea mariana (black spruce) preparations from seedling root tips and embryogenic cultures
}

\author{
K. K. NKONGOLO*† \& K. KLIMASZEWSKA \\ tDepartment of Biological Sciences, Laurentian University, Sudbury, Ontario, P3E 2C6, $\ddagger$ Petawawa National Forestry \\ Institute, Natural Resources, Chalk River, Ontario, Canada, KOJ 110
}

\begin{abstract}
The effect of hydroxyurea and colchicine solutions on mitotic index was investigated in embryogenic suspensions and in seedling root tips of Picea mariana. Hydroxyurea treatment and 0.6 per cent colchicine solution significantly increased the quantity of mitotic cells which were mostly in the metaphase stage. The highest mitotic index was observed in cells of embryogenic suspensions. The embryogenic lines were cytologically stable and their utilization for karyotype studies and technique development holds great potential. The arm ratios and relative chromosome length values showed the same trends between embryogenic cultures and seedling root tips and among the five black spruce populations studied. This study shows that the black spruce karyotype is asymmetric and semi-advanced, as in Larix and Abies. Three pairs of chromosomes are of the sm-type with submedian centromeres. One pair is median-submedian ( $\mathrm{msm})$, six pairs are $\mathrm{m}$-type having median centromeres and two pairs are metacentric or M-type.
\end{abstract}

Keywords: colchicine, embryogenic line, hydroxyurea, karyotype, mitotic index, Picea mariana.

\section{Introduction}

The genus Picea comprises some 40-60 species widely distributed over cooler regions of the northern hemisphere down to the Tropic of Cancer. Of these species, red spruce ( $P$. rubens), black spruce ( $P$. mariana) and white spruce $(P$. glauca) are of great economic importance in North America and are widely used for paper pulp. Black spruce is the most common tree in many areas of the boreal forest, particularly so in Ontario and Québec. Cytogenetic information in the genus Picea is preliminary and limited to chromosome counts and size due to difficulties in consistently obtaining mitotic spreads with suitable chromosome size. Moreover, many workers have found conifer tissues recalcitrant to chemical treatments, making molecular and cytological studies more difficult than with other plant groups. Thus, the phylogenetic relationships among spruce taxa have been mostly investigated by morphological analysis, crossing and geographical distribution (Wright, 1955; Mikkola, 1969; Fowler, 1983).

\footnotetext{
*Correspondence.
}

This is the first in a series of detailed studies of spruce cytogenetics including karyotype comparisons, chromosome banding, and physical mapping of repeated DNA sequences. In the present study we show that embryogenic cultures are suitable for spruce cytogenetic studies. We compared chromosome karyotypes and mitotic stability in preparations from embryogenic cultures and root tips. Furthermore, the effect of hydroxyurea and colchicine concentration on mitotic index was investigated in both types of material.

\section{Materials and methods}

Seeds of two black spruce (Picea mariana Mill.) lots, 8810399 and 8810404 collected in Beaver, New Brunswick, were obtained from the National Seed Center, Petawawa National Forestry Institute, Chalk River, Ontario. Additional seeds of two other lots, 82339 and 74122 collected in Dorion (Québec) and Dufour (Québec), respectively, were provided by the Provincial Ministry of Forestry, Berthierville (Québec). The seeds were placed in clear polycarbonated 'Petawawa germination boxes' containing wet 'Kimpak' 
cellulose paper and kept in a germinator at $30^{\circ} \mathrm{C}$ temperature for $12 \mathrm{~h}$ under fluorescent lights and $8 \mathrm{~h}$ at $20^{\circ} \mathrm{C}$ in darkness. Seedlings with roots $2-4 \mathrm{~cm}$ long were collected for pretreatment. Embryogenic cultures of two spruce lines (R4F14 and 51) were used to compare both the karyotypes and chromosomal mitotic behaviour of the cultured cells. These cultures were established and maintained as previously described (Cheliak \& Klimaszewska, 1991). The embryonal masses of R4F14 were maintained in culture for 3.5 years and of 51 for 2 years.

Seedlings and embryonal masses of these black spruce lines were incubated for $18 \mathrm{~h}$ in liquid, half strength LM medium (Litvay et al., 1981; Cheliak \& Klimaszewska, 1991) that contained 1.25 mm hydroxyurea (Sigma), which blocks the cell cycle in S-phase. The material was kept in $125 \mathrm{~mL}$ Erlenmeyer flasks placed on a shaker at 125 r.p.m. at $24^{\circ} \mathrm{C}$. After three rinses with medium without hydroxyurea, the material was incubated for $6 \mathrm{~h}$ in fresh medium followed by treatment with the medium containing 0.6 per cent or 0.06 per cent $(\mathrm{w} / \mathrm{v})$ colchicine (Sigma) for $18 \mathrm{~h}$. At this time the root tips were excised from the seedlings and both types of material were fixed in 3:1 ethanol:glacial acetic acid for $1 \mathrm{~h}$. The samples were stained with acetocarmine or aceto-orcein after hydrolyzation with $1 \mathrm{~N} \mathrm{HCl}$ for $30 \mathrm{~min}$ at room temperature. Non-synchronized material was treated similarly except that incubation in medium with hydroxyurea was omitted. Additional checks were prepared for root tip material. This consisted of excising root tips from seedlings directly after germination without pretreatment in the medium. In this case, root tips were treated in an aqueous solution of colchicine. The fixing, hydrolyzation and staining steps were carried out as described above.

\section{Cytological analyses}

Prophase, metaphase and anaphase cells were analysed in all the preparations derived from embryogenic cell suspensions and root tips so as to compare chromosomal behaviour. Chromosomes were counted in 100 metaphase and pro-metaphase cells for each treatment. Mitotic index was calculated as the percentage of cells at prophase, metaphase and anaphase. These data were transformed by arcsin $\sqrt{\text { percentage }}$ to improve their normality. The transformed data were then analysed as a completely randomized experiment, each experimental unit containing five slides. An analysis of variance and the LSD test were computed using MSTAT-C statistical programs (MSTAT Development Team, 1988).

The karyotype analysis was made using several representative cells for each treatment in which the chromosomes were well-separated and secondary constrictions visible. Cells with the desirable chromosome conditions were photographed at $\times 630$ under oil using a Zeiss microscope.

The chromosomes of the photographed cells were numbered from 1 (the longest) to 12 (the shortest). To measure the chromosomes, a fine thread was laid over each chromosome in the photograph, marked and then measured in millimeters. All measurements were conducted twice. Homologous pairs were arranged by comparing centromere positions and the presence of secondary constrictions. Averages of the paired chromosomes were taken for total length, relative length, index and ratio. A relative value was used as the standard for chromosome lengths. The relative length of a given chromosome was determined by dividing the absolute chromosome lengths by the sum of all the chromosome lengths and was expressed as a percentage of the total (Tjio \& Hagberg, 1951). The ratio of the long arm to the short arm was used to identify centromere position for each chromosome. The nomenclature system of Levan et al. (1964) was used to determine the chromosome types as median, submedian or subterminal. Diagrammatic presentations for the chromosomes from embryogenic suspensions and root tips were developed according to arm ratios and relative lengths. The idiogram representing black spruce was based on averages for relative lengths and arm ratios. Karyotypes established from root tip preparations were compared to those of embryogenic cultures.

\section{Results and discussion}

Samples from embryogenic cultures consistently resulted in larger numbers of cells at different mitotic stages than samples from root tips (Fig. 1). Furthermore, chromosomes were morphologically less condensed and showed characteristic morphology in higher frequencies than root tip preparations. This may be ascribed to the fact that cells in suspension are exposed more readily to chemical treatment for revealing detailed karyotypes while cells in meristems have cell walls that can provide barriers. Our attempt to weaken root tip cell walls using a cellulase and pectinase solution to facilitate better penetration of chemicals resulted in an increased number of chromosome spreads free of cytoplasms but did not significantly improve the visualization of secondary structures (data not shown). When seedlings were pretreated with colchicine in the medium rather than in the water the secondary constrictions of root tip chromosomes were readily identified. This made the comparison of chromosome karyotypes of embryogenic cultures and root tips described in this study accurate. 

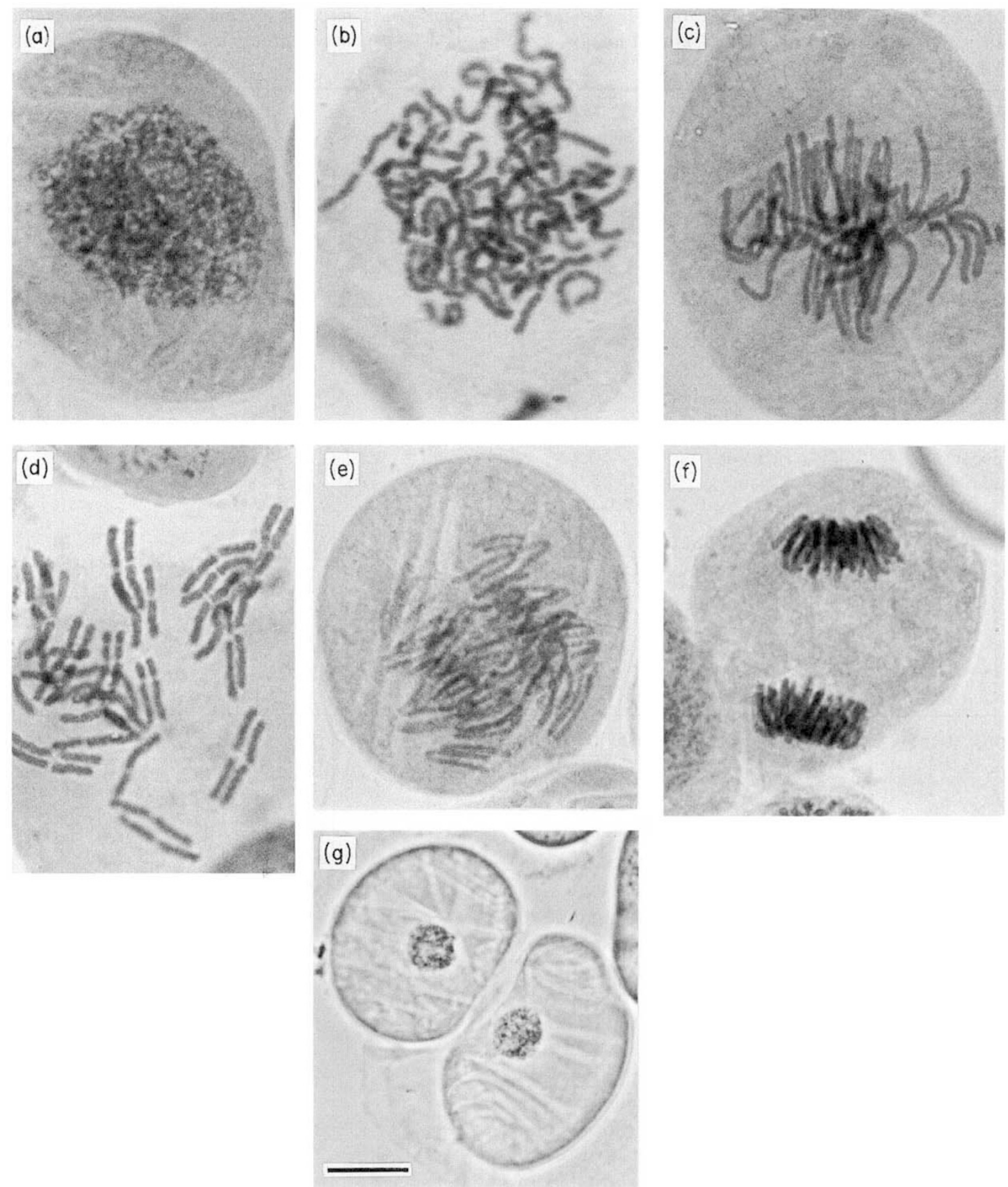

Fig. 1 Major stages in the mitotic sequence of black spruce, Picea mariana, embryogenic cultures: (a) interphase, (b) prophase, (c) metaphase, (d) meta-anaphase, (e) anaphase, (f) telophase and $(\mathrm{g})$ early interphase. Bar represents $10 \mu \mathrm{m}$.

The highest mitotic index ( $\mathrm{MI}=38$ per cent $)$ was obtained in cell suspension preparations pretreated with $1.25 \mathrm{~mm}$ hydroxyurea and 0.6 per cent colchicine solutions (Table 1). In general the results of this study show a significant increase of mitotic index when hydroxyurea was used in both cell suspension cultures and root tips (Table 1). This agrees with the observations of Schubert et al. (1993) showing high mitotic index in Vicia faba seedling root tips treated with hydroxyurea and with those of Matthews (1983) in 
Table 1 Percentages of cells at prophase, metaphase, anaphase, telophase and interphase and mitotic index (arcsin values in parentheses) in preparations from black spruce root tips, seedlings and cell suspensions pretreated with hydroxyurea and colchicine

\begin{tabular}{|c|c|c|c|c|c|c|c|}
\hline Material & Pretreatment & $\begin{array}{l}\text { Prophase } \\
(\%)\end{array}$ & $\begin{array}{l}\text { Metaphase } \\
(\%)\end{array}$ & $\begin{array}{c}\text { Anaphase } \\
(\%)\end{array}$ & $\begin{array}{c}\text { Telophase } \\
(\%)\end{array}$ & $\begin{array}{c}\text { Interphase } \\
(\%)\end{array}$ & $\begin{array}{l}\text { Mitotic } \\
\text { index* } \\
(\%)\end{array}$ \\
\hline Root tips & $\begin{array}{l}0.06 \% \text { colchicine } \\
0.6 \% \text { colchicine }\end{array}$ & $\begin{array}{l}4.3 \\
2.7\end{array}$ & $\begin{array}{l}13.3 \\
12.8\end{array}$ & $\begin{array}{l}0.5 \\
0.0\end{array}$ & $\begin{array}{l}14.7 \\
16.3\end{array}$ & $\begin{array}{l}65.6 \\
68.3\end{array}$ & $\begin{array}{l}17.8(25.0) \\
15.5(23.2)\end{array}$ \\
\hline \multirow[t]{3}{*}{ Seedlings } & $\begin{array}{l}0.06 \% \text { colchicine } \\
0.6 \% \text { colchicine }\end{array}$ & $\begin{array}{l}0.2 \\
0.1\end{array}$ & $\begin{array}{l}0.3 \\
6.2\end{array}$ & $\begin{array}{l}0.0 \\
0.0\end{array}$ & $\begin{array}{r}14.7 \\
9.3\end{array}$ & $\begin{array}{l}85.3 \\
84.5\end{array}$ & $\begin{array}{l}0.5(1.3) \\
6.2(14.4)\end{array}$ \\
\hline & $\begin{array}{l}1.25 \mathrm{~mm} \text { hydroxyurea } \\
+0.06 \% \text { colchicine }\end{array}$ & 0.4 & 11.7 & 0.0 & 9.8 & 74.9 & $12.1(20.4)$ \\
\hline & $\begin{array}{l}1.25 \mathrm{~mm} \text { hydroxyurea } \\
+0.6 \% \text { colchicine }\end{array}$ & 0.5 & 15.6 & 0.0 & 12.4 & 66.7 & $16.1(23.7)$ \\
\hline \multirow{3}{*}{$\begin{array}{l}\text { Cell suspensions } \\
\text { from embryogenic } \\
\text { lines }\end{array}$} & $\begin{array}{l}0.06 \% \text { colchicine } \\
0.6 \% \text { colchicine }\end{array}$ & $\begin{array}{l}3.1 \\
5.0\end{array}$ & $\begin{array}{r}4.8 \\
14.5\end{array}$ & $\begin{array}{l}0.0 \\
0.0\end{array}$ & $\begin{array}{r}11.1 \\
9.8\end{array}$ & $\begin{array}{l}81.0 \\
70.6\end{array}$ & $\begin{array}{r}7.9(16.3) \\
19.5(26.2)\end{array}$ \\
\hline & $\begin{array}{l}1.25 \mathrm{~mm} \text { hydroxyurea } \\
+0.06 \% \text { colchicine }\end{array}$ & 7.0 & 9.5 & 0.5 & 13.5 & 68.0 & $17.0(24.4)$ \\
\hline & $\begin{array}{l}1.25 \mathrm{~mm} \text { hydroxyurea } \\
+0.6 \% \text { colchicine }\end{array}$ & 11.0 & 25.4 & 1.4 & 14.9 & 47.3 & $37.8(37.9)$ \\
\hline $\mathrm{LSD}_{0.05}$ & & - & - & - & - & - & $3.2(10.3)$ \\
\hline $\mathrm{LSD}_{0.01}$ & & - & - & - & - & - & $9.7(18.5)$ \\
\hline
\end{tabular}

*Average of five replications. Angular transformed means in parentheses.

synchronized carrot cell suspension cultures. Significant improvement of the mitotic index was also observed when colchicine concentration was increased from 0.06 per cent to 0.6 per cent in cell suspensions and seedlings pretreated in the LM medium (Table 1). No significant difference was obtained in root tip preparations pretreated with 0.06 per cent and 0.6 per cent colchicine solutions in water (Table 1).

We observed a high variation in length between corresponding chromosomes in various cells (Fig. 2). This variation was higher in root tip preparations than in cell suspension preparations. According to Borzan (1977), length variation between chromosomes from cell to cell is caused by the 'sticky' phenomenon, described as an entanglement of chromatin fibres of unrelated chromosomes. Such a phenomenon was not observed in our preparations, suggesting that chromosome length variation may be related to artificial causes such as chemical treatment. The exact mechanism causing this variation is unknown.

The somatic chromosome number was found to be $2 n=24$, which confirms the results of previous work (Morgenstern, 1962). B chromosomes that have been

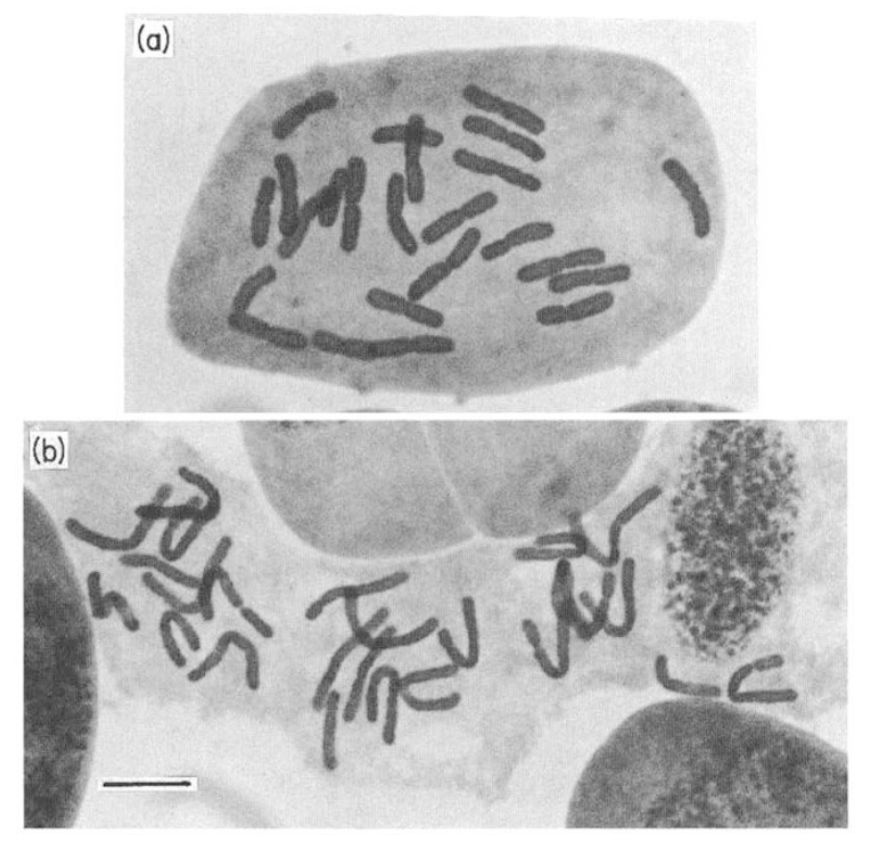

Fig. 2 (a-b) Metaphase chromosome spreads from black spruce root tips. Note the high variability in chromosome contractions between the two cells. Bar represents $10 \mu \mathrm{m}$. 
detected in other spruce species (Kruklis, 1971; Moir \& Fox, 1976; Teoh \& Rees, 1977) were absent in our materials. The lack of B chromosomes in these populations may be due to natural selection (Moir \& Fox, 1976). Aneuploid cells, too, were not observed in our embryogenic lines. All the cells from embryogenic cultures showed normal mitotic behaviour at all stages, including prophase, metaphase, anaphase and telophase (Fig. 1). The arm ratios and relative chromosome values did not show variation between embryogenic cultures and root tips or among the different lines studied. Recent molecular studies on genetic stability of black spruce embryogenic cultures showed no variation within the clones (Isabel et al., 1993). The basis for the apparent genetic stability of these embryogenic cultures is unknown but may be related to their embryogenic character (Eastman et al., 1991). Preliminary studies reported similar genetic stability for tissue culture lines of Eucalyptus (N. S. Hague, N. W. Fish and M. Kei, 1992, personal communication), Larix (J. Wyman, N. Brassard, D. Filpo and S. Laliberté, 1992, personal communication) and Norway spruce (B. Heinze, R. Westcott and J. Schmidt, personal communication, 1992), suggesting that this may be a general phenomenon in woody tree species. In herbaceous plants, however, the occurrence of chromosome rearrangements as well as numerical changes in cultured plant tissues is very common (Ashmore \& Gould, 1981; Murata \& Orton, 1983).

The average relative lengths and chromosome indices are presented in Fig. 3. The customary manner of researching karyotypes is to organize chromosomes in a series from 1 to 12 on the basis of their lengths in the photograph. However, this method does not take into consideration the division stages of the cell under investigation. Some of the cells could be, for example, at the prometaphase stage; most often cells are analysed at metaphase but could be also analysed at anaphase (Borzan, 1977). Calculation of relative chromosome lengths avoids the variability of individual chromosome length caused by division stages of the cells and differences in chromosome contraction among cells (Fig. 2). Such systematization of karyotype analysis will make comparisons of intra- and interspecific spruce karyotypes more accurate.

The long arm/short arm ratio was used to determine the centromere position of each chromosome according to the Levan et al. (1964) system as modified by Schlarbaum \& Tsutchiya (1984). Chromosomes 1, 10 and 12 were of the sm-type, with submedian centromeres. Chromosome 9 was median-submedian (msm). Chromosomes 2, 4, 5, 6, 7 and 11 were all m-type
Fig. 3 Comparison of diagrammatic presentations of the black spruce genome using embryogenic cultures and root tips. Relative lengths ( $\mathrm{x}$-axis) were derived by averaging the percentages of the total chromosome length for individual chromosomes. The chromosome index is the average of the short arm to long arm ratios (y-axis). $\square$, Embryonic cultures; 0 , root tips.

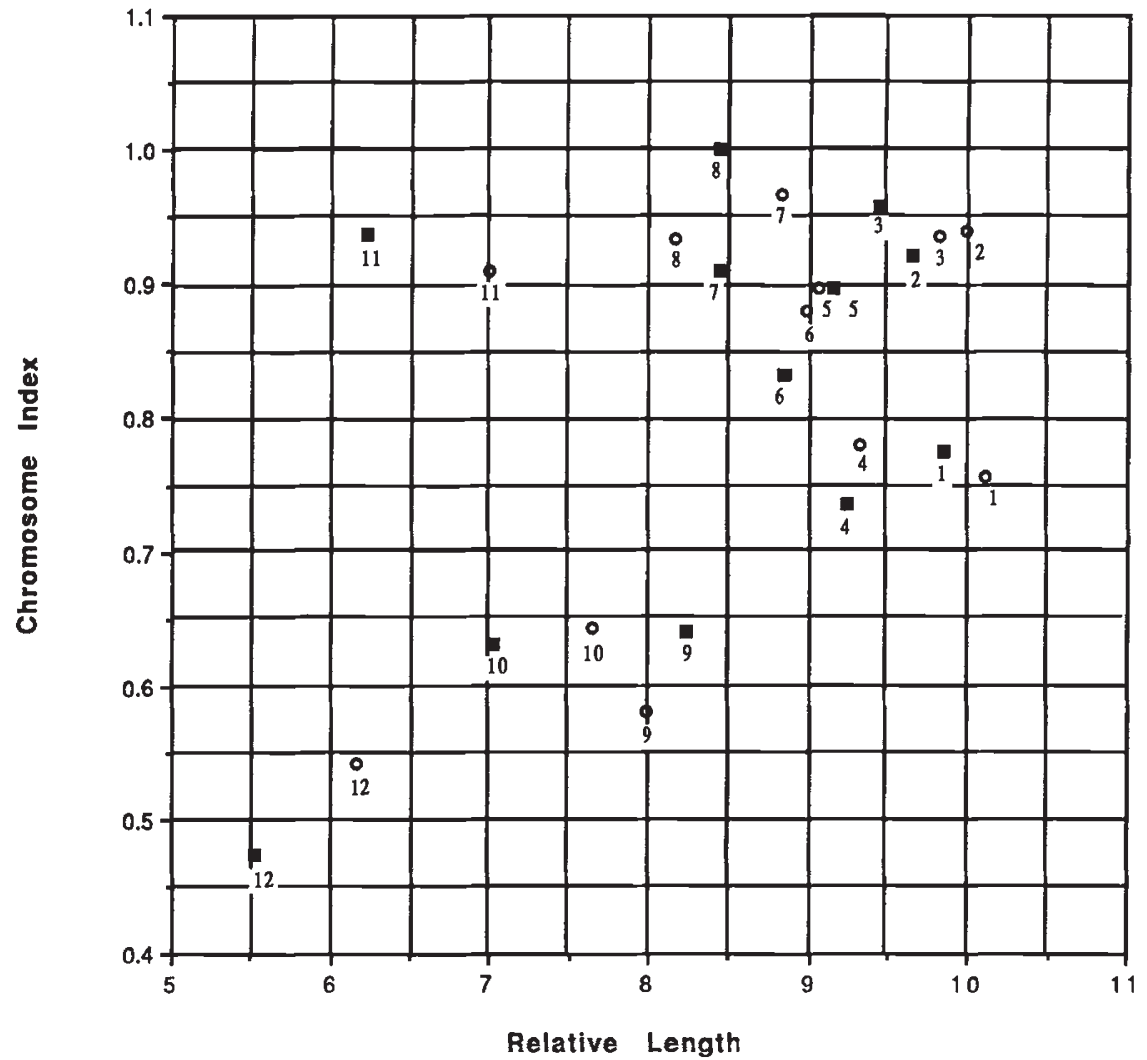


having median centromeres and chromosomes 3 and 8 were metacentric or M-type. These data, as presented in an idiogram (Fig. 4), indicate that the karyotype of black spruce is asymmetrical. Such a karyotype can be considered as 'semi-advanced' as in Larix (Simak, 1964, 1966) and Abies (Mergen \& Burley, 1964). In Pinus, on the other hand, the karyotype is relatively primitive having median centromeres and small differences in relative size (Saylor, 1983).

Chromosomes 1, 3, 5, 6 and 10 have a distinctive secondary constriction on one of their arms. Based on this distinctive morphology, these five chromosomes, along with chromosome 12 (the smallest and submedian), may be considered useful cytological references both for studying cytotaxonomical relationships of black spruce with other spruce species and for charting karyotypic evolution. In many plant species, the secondary constrictions are associated with the nuclear region (Schlarbaum et al., 1983). To ascertain the position of the nucleolar organizer region in black spruce, meiotic studies are required since the information provided by mitotic analysis is limited. As presented in Fig. 4, all the chromosomes can be easily identified, except chromosomes 7 and 8 which can be reversed as they are morphologically similar. Chetty et al. (1970), pointed out that the risk of reversal of the chromosome order cannot be disregarded if the difference between chromosome length is very small. In the case of black spruce, chromosomes 7 and 8 have exactly the same relative length and do not have any distinctive secondary constriction. Therefore, these two chromosomes have a high probability of being confused. Chromosomes 1 and 2 also have the same relative length but differ by the presence of a secondary constriction on chromosome 1 . Thus the possibility of misidentification is less likely.

The lack of success in previous spruce karyotyping may be ascribed in part to the use of inappropriate pretreatment methods and plant material. Morgenstern (1962) failed to visualize secondary constrictions in black and red spruce chromosomes and focused his study on chromosome groups rather than on individual chromosomes. Hizume (1988) and Hizume et al. (1991) did karyomorphological studies on important conifers in Asia. They observed secondary constrictions in some spruce chromosomes but their work was based on general chromosome morphology which did not generate a detailed karyotype of any spruce species. However, they were successful in identifying homologous chromosomes in Picea jezoensis using fluorescent chromosome banding. Recently, Brown et al. (1993) working with white spruce (Picea glauca) experienced problems obtaining metaphase preparations with well-separated chromosomes because of the
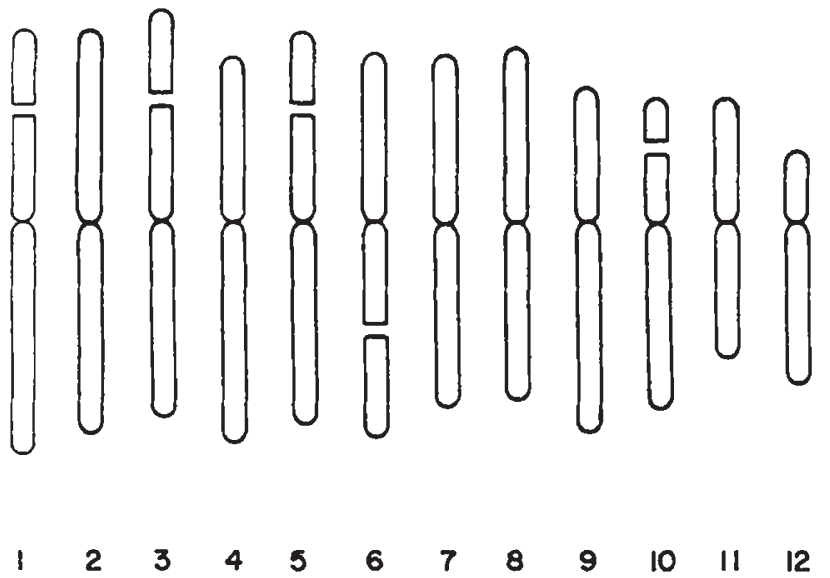

Fig. 4 Idiogram representing the chromosomes of black spruce. The chromosomes are numbered by decreasing order according to chromosome length.

long size of the chromosomes. However, their preliminary data on chromosome morphology are very useful and suggest that white spruce and black spruce chromosomes have distinctive morphological characters. As their data were based on very limited seed material of one line and their chromosome measurements were based on absolute lengths rather than relative lengths, cytological differences between these spruce species cannot be established at this time.

This study shows that embryogenic cultures of black spruce are suitable for cytogenetic analysis. In addition to the high number of prophase, metaphase and anaphase cells obtained, the chromosomes exhibit distinctive secondary constrictions in most of the cells in all the preparations. Because embryonal masses are cytologically stable, their utilization for karyotype studies and technique development holds great potential.

We also demonstrated that hydroxyurea and a highly concentrated colchicine solution significantly increase the mitotic index values in both cell suspensions and seedling root tips. Finally, we established that the black spruce karyotype is semi-advanced and different from the primitive Pinus karyotype.

\section{Acknowledgements}

We express our appreciation to Petawawa National Forestry Institute (PNFI) Seed Center and the Ministry of Forestry, Berthierville, Québec for the seeds of black spruce used in this study. We are also thankful to $\mathrm{Mr}$ Gary Scheer (PNFI) for his assistance with seed germination. This study was supported by a research award to K. K. N. from the International Fund for Interinstitutional Cooperation, 'AUPELF. FICU', Montreal and by 
Laurentian University Research Fund Project 201018. Additional support was provided by Natural Resources, Petawawa National Forestry Institute, Chalk River, Ontario.

\section{References}

ASHMORE, S. E. AND GOULD, A. R. 1981. Karyotype evolution in tumor derived plant tissue culture analysed by Giemsa C-banding. Protoplasm, 106, 297-308.

BROWN, G., AMARASINGHE, v., KISS, G. AND CARLSON, J. E. 1993. Preliminary karyotype and chromosomal localization of ribosomal DNA sites in white spruce using fluorescence in situ hybridization. Genome, 36, 310-316.

BORZAN, z. 1977. Contribution to the karyotype analysis of the european black pine (Pinus nigra Arn.). Ann. Forest, 8, 29-50.

CHELIAK, W. M. AND KLIMASZEWSKA, K. 1991. Genetic variation in somatic embryogenic response in open-pollinated families of black spruce. Theor. Appl. Genet., 82, 185-190.

CHETTY, C. K. R., UPADHAYA, L. P. AND KEDHARNATH, S. 1970. Estimation of risk of reversal of arms and order of chromosomes in karyotype analysis of Pinus roxburghii Sarg. Indian Forester, 96, 811-816.

EASTMAN, P. A. K., WEBSTER, F. B., PITEL, J. A. AND ROBERT, D. R. 1991. Evaluation of somaclonal variation during somatic embryogenesis of interior spruce (Picea glauca engelmannii complex) using culture morphology and isozyme analysis. Plant Cell Reports, 10, 425-430.

FOWLER, D. P. 1983 . The hybrid black $\times$ Sitka spruce, implications to phylogeny of the genus Picea. Can. J. For. Res., 13, 108-115.

HIZUME, M. 1988. Karyomorphological studies in the family Pinaceae. Mem. Fac. Educ. Ehine Univ. Ser. III Nat. Sci., 8, 1-108.

HIZUME, M., KITAZAWA, N., GU, Z. AND KONDO, K. 1991. Variation of fluorescent chromosome band in Picea brachytyla var. complanata collected in Yunnan, China. Kromosomo, II63-64: 2149-2158.

ISABEL, N., TREMBLAY, L., MICHAUD, M., TREMBLAY, F. M. AND BOUSQUET, J. 1993. RAPDs as an aid to evaluating the genetic integrity of somatic embryogenesis-derived populations of Picea mariana (Mill.). Theor. Appl. Genet., 86, 81-87.

KRUKLIS, M. v. 1971. Supplementary chromosomes in gymnosperms (in Picea obovata LBD as an example). Dokl. Akad. Nauk DDR. Seiya Biologiya, 196, 44-47 (in Russian).
LEVAN, A., FREDGA, K. AND SANDBERG, A. A. 1964. Nomenclature for centrometric position on chromosomes. Hereditas, $\mathbf{4 2}$, 201-220.

LITVAY, J. D., JOHNSON, M. A., VERMA, D., EINSPAHR, D. AND WERGRAND, K. 1981. Conifer suspension culture medium development using analytical data from developing seeds. Tech. Pap. Series, Just. Paper. Chem., Appleton, WI, USA, 115, 1-17.

MATTHEWS, B. F. 1983. Isolation of mitotic chromosomes from partially synchronized carrot $(D$. carota) cell suspension cultures. Plant Sci. Lett., 31, 165-172.

Mikкola, L. 1969. Observations on interspecific sterility in Picea. Ann. Bot. Fennici, 6, 258-339.

MERGEN, F. AND BURLEY, J. 1964. Abies karyotype analysis. Silvae Genet., 13, 63-68.

MOIR, R. B. AND FOX, D. P. 1976. Supernumerary chromosomes and growth rate in Picea abies (Bong.) Carr. Silvae Genet., 25, 139-141.

MORGENSTERN, E. K. 1962. Note on chromosome morphology in Picea rubens Sarg. and Picea mariana (Mill.). Silvae Genet., 11, 163-164.

MURATA, M. AND ORTON, T. J. 1983. Chromosome structural changes in cultured celery cells. In Vitro, 19, 83-89.

MSTAT DEVELOPMENT TEAM. 1988. MSTAT-C: a microcomputer program for the design, management and analysis of agronomic research experiments. Michigan State University, East Lansing.

SAYLOR, L. C. 1983. Karyotype analysis of the genus Pinus subgenus Strobus. Silvae. Genet., 32, 119-124.

SCHLARBAUM, S. E. AND TSUCHIYA, T. 1984. The chromosomes of Cunninghamia konishii, C. lanceolata and Taiwania cryptomerioides (Taxodiaceae). Pl. Syst. Evol., 145, 169-181.

SCHLARBAUM, S. E., JOHNSON, L. C. AND TSUCHIYA, T. 1983. Chromosome studies of Metasequoia glyptostroboides and Taxodium distichum. Bot. Gaz., 144, 559-565.

SCHUBERT, I., DOLEZEL, J., HOUBEN, A., SCHERTHAN, H. AND WANNER, G. 1993. Refined examination of plant metaphase chromosome structure at different levels made feasible by new isolation methods. Chromosoma, 102, 96-101.

SIMAK, M. 1964. Karyotype analysis of Siberian larch (Larix sibirica Ledb. and Larix sukaczewii Dyl.). Stud. Forest. Suec., 17, 1-15.

SIMAK, M. 1966. Karyotype analysis of Larix griffithiana Carr. Hereditas, 56, 137-141.

TEOH, S. B. AND REES, H. 1977. B-chromosomes in white spruce. Proc. R. Soc, Lond. B., 198, 325-344.

TJIO, J. H. AND hagBerg, A. 1951. Cytological studies on some X-ray mutants of barley. Anales Aula Dei., 2, 149-167.

WRIGHT, J. W. 1955. Species crossability in spruce in relation to distribution and taxonomy. Forest Sci., 1, 319-349. 